\title{
MODIFIED SCREEN-PRINTED ELECTRODE FOR DETERMINATION OF IMIDACLOPRID IN WATER SAMPLES: A PRELIMINARY STUDY
}

\author{
AZRILAWANI AHMAD*, NUR ANIS ZAFIRAH ZAINORDIN AND NUR AMIRA JAAFAR
}

School of Marine and Environmental Sciences, Universiti Malaysia Terengganu, 21030 Kuala Nerus, Terengganu.

\section{*Corresponding author: azrilawani.ahmad@umt.edu.my}

\begin{abstract}
A preliminary assessment of a simple and rapid electrochemical method was carried out to analyse imidacloprid (IMI) in water samples using cyclic voltammetry (CV) based on modified screen-printed gold electrode (SPGE). Self-assembled monolayer (SAM) was optimized using 11-mercaptoundecanoic acid (11MUA) with several parameters such as scan rates, type of supporting electrolyte, and $\mathrm{pH}$ of the supporting electrolyte. The modified SPGE showed high suppressed current against the potential due to the formation of a monolayer on the electrode surface. Surface morphology of the electrode was analysed using Scanning Electron Microscopy (SEM) confirming that 11-MUA was present on the modified SPGE. The water samples were collected from GM Peladang, Kuala Terengganu and two locations at Universiti Malaysia Terengganu. Method detection limit was expressed as limit of detection (LOD) and limit of quantification (LOQ) for modified SPGE which were calculated at 3.784 and $12.613 \mathrm{mg} / \mathrm{L}$ in water samples, respectively. This study showed that the reduction peak current observed on the modified electrode was lower compared with oxidation peak current. Hence, gold is unsuitable for IMI detection.
\end{abstract}

Keywords: Imidacloprid, electrochemical detection, screen-printed gold electrode, scanning electron microscope

\section{Introduction}

In the past decades, the use of pesticides has significantly increased due to the progress in worldwide agricultural production. In order to improve agricultural productivity, farmers usually use different types of pesticides including herbicides, insecticides, fungicides and others for protection of crops against pests. The pesticide policies in Europe and America focus on reducing pesticide applications because people start to be concerned about the risk of pesticides towards the human body (Durovic et al., 2016). However, there are few developing countries including Malaysia, Brazil, South Africa Uruguay and Argentina that maintain pesticide usage (Halimatunsadiah et al., 2016). Although the use of pesticides gives a lot of advantages in agriculture, they also have negative impact on human health and environment (Guzsvany et al., 2011).

Imidacloprid (IMI) has become the most widely used insecticide for pest control on crops since its discovery and utilization. It is one of the insecticides most purchased in the world for agricultural purpose. As the usage of IMI insecticide has been growing fast, many adverse effects have also been identified. This substance is potentially harmful to animals and humans as it poses serious health hazards. The International Agency for Research on Cancer (IARC) reported that IMI caused a few symptoms such as skin or eye irritation, dizziness, difficulty in breathing or vomiting after exposure to the insecticide for too long but it did not cause cancer. As reported by European Food Safety Authority (EFSA)
Scientific Report (2008), IMI is fully taken up by oral administration, does not bioaccumulate and is excreted primarily by urine within the toxicological assessment. IMI insecticide also has high solubility in aqueous solution and will provide a serious threat to water and soil quality. Moreover, animals will also be exposed to pesticides through food and water sources.

IMI is known for its chemical properties, a polar compound with high solubility in water, non-volatile and very persistent in water and soil as it has longer half-life (Sabourmoghaddam et al., 2015). This makes it easy for IMI to enter into aquatic ecosystems through water drainage and run-off into agricultural areas. Besides, IMI is used over the fields and agricultural farms as it is sprayed almost every day to protect crops. Accumulation of toxic substances from the pesticides and their degraded products flow into water body, atmosphere and soils, and affect human health and the environment (Hashim et al., 2016). Besides, IMI can leach and transport to the surface of water bodies through heavy rain, surface runoff or soil erosion due to high water solubility (Kumar et al., 2013). The main routes of IMI into the environment are by photolysis process and uptake from plant (Liu et al., 2015). However, in the absence of light, IMI breaks down slowly in water and soil, leading to the distribution of IMI to the environment which can cause an adverse effect on human life. Hence, the public has expressed major concern about the impact of IMI and its product towards the environment. Figure 1 shows the chemical structure of IMI. 
<smiles>O=[N+]([O-])/N=C1\NCCN1Cc1ccc(Cl)nc1</smiles>

Figure 1: Chemical structure of Imidacloprid.

Besides, IMI also causes the degradation in soil, contamination on surface of water and air pollution due to the spraying of IMI on the crops. Leaching of chemicals from this insecticide will contaminate the water body. There is potential for IMI to enter into aquatic systems through a variety of vectors, including spray drift, atmospheric deposition, soil erosion and runoff (Struger et al., 2017). The neonicotinoids group is expected to enter the groundwater when it rains heavily because of lower content in organic soil as they slower bound in soil (Goulson, 2013). As IMI gives adverse impact to human health and environment, the development of an electrochemical method is needed to determine the concentration of IMI in water samples.

According to Tonle \& Ngameni (2010), there are few analytical techniques that have been used for the analysis of pesticides, such as flourimetry, capillary electrophoresis, spectrophotometry and mass spectroscopy which can detect their residues in surface of water, soil and air. However, these methods have some limitations because they need to be performed by experienced technicians, and are expensive and time consuming. Cyclic voltammetry is one of the most popular electrochemical methods because it is inexpensive, simple and less time consuming. Therefore, in this study, the development of the modified screenprinted gold electrode (SPGE) was used for the determination of IMI in water samples.

\section{Materials and Methods Chemicals}

An analytical standard of imidacloprid was supplied by Dr. Ehrenstorfer GmbH, Germany. Methanol, potassium hydroxide and potassium chloride were purchased from Merck, Germany. Potassium ferrocyanide and acetic acid were supplied by R\&M Chemicals, UK. Sodium hydroxide, sodium nitrate, boric acid, ortho-phosphoric acid, acetonitrile, n-hexane and 11- mercaptoundecanoic acid were purchased from Sigma Aldrich, US. All chemicals and reagent were of analytical grade and were used without further purification.

\section{Instrumentation}

Electrochemical measurements were performed using AutoLab Model PGSTAT30 from Metrohm Ltd, Heriasu, Switzerland. Screen-printed gold electrode (SPGE) (DropSens 220BT) from DropSens, Spain that consists of a gold working electrode and counter electrode, and a silver/silver chloride reference electrode was used in this study. Scanning electron microscope (SEM) JSM-6360LA from JEOL, United States was used for the electron micrograph scanning.

\section{Electrode Cleaning Process}

Electrode cleaning is an important step before the measurement to remove the possible impurities that accumulate on the surface of working electrode, thus it will help to improve the performance of the SPGE for the detection process in cyclic voltammetry. The surface of the SPGE was cleaned in $1 \mathrm{M}$ hydrochloric acid, rinsed with deionized water and sonicated in ethanolic solution for two to three minutes prior to analysis. For the analysis, $\mathrm{CV}$ was conducted in the potential range of -0.2 to $0.8 \mathrm{~V}$ in the presence of $5 \mathrm{mM} \mathrm{K}{ }_{4} \mathrm{Fe}(\mathrm{CN})_{6}$ in $0.1 \mathrm{KCl}$, with the scan rate of $0.05 \mathrm{mV} / \mathrm{s}$.

\section{Optimization of Parameters for Electrochemical Measurement}

Several conditions were optimized in order to achieve the optimum parameter for electrochemical measurement using SPGE. The parameters were scan rates, type of supporting electrolyte and $\mathrm{pH}$ of the supporting electrolyte.

\section{Scan rates}

Different values of scan rate were measured using cyclic voltammetry for bare SPGE. The scan rate values were tested at 50,100, 150, 200 and $250 \mathrm{mV} / \mathrm{s}$ to obtain the cyclic voltammogram which gave the best result for IMI detection.

\section{Types of supporting electrolytes}

A few types of supporting electrolytes were used for the optimization process such as $5 \mathrm{mM} \mathrm{K} \mathrm{K}_{4} \mathrm{Fe}(\mathrm{CN})_{6}$ in $0.1 \mathrm{M}$ $\mathrm{KCl}, 5 \mathrm{mM} \mathrm{K}{ }_{4} \mathrm{Fe}(\mathrm{CN})_{6}$ in Britton-Robinson buffer (B-R buffer), potassium hydroxide $(\mathrm{KOH})$ and sodium nitrate $\left(\mathrm{NaNO}_{3}\right)$. The supporting electrolyte that exhibited a proper shape and had lower peak separation was employed for the next measurement.

\section{pH of the supporting electrolyte}

Different $\mathrm{pH}$ values of 5, 6, 7, 8 and 9 were prepared for IMI detection in the optimized supporting electrolyte. $\mathrm{pH}$ 
of each solution was adjusted using either $5 \%$ of dilute $\mathrm{HCl}$ or $1 \mathrm{M} \mathrm{KOH}$. $\mathrm{pH}$ value that gave good performance was used for further measurement.

\section{Modification and Characterization of Screen Printed Gold Electrode}

Self-assembled monolayer (SAM) was performed on the surface of SPGE with 11-mercaptoundecanoic acid (11-
MUA). The reagent solution was prepared by dissolving 11-MUA in absolute ethanol for final concentration of 5 $\mathrm{mM}$. The SPGE was immersed in 11-MUA solution for 20 hours at room temperature. Then, SPGE was washed with distilled water and dried prior to the electrochemical measurement. Figure 2 shows the SPGE immersed in the reagent solution.

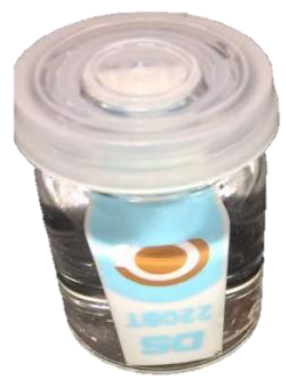

Figure 2: Immobilization of 11-MUA on the surface of SPGE.

After the electrode modification, SEM was used to observe the physical characterization of the surface morphology of both bare and modified SPGE. The electrodes were coated with gold before being examined under SEM for conductivity to avoid charging effect. Both electrodes were observed at magnification of x3500 with the accelerating voltage at $15 \mathrm{kV}$. Meanwhile, chemical characterization (CV) was carried out using parameters which have been stated in previous section.

\section{Preparation of IMI Standard}

A serial dilution of IMI ranging between 1-10 mg/L were prepared in methanol. The relationship between concentrations of IMI and peak current was determined in $\mathrm{CV}$ experiment.

\section{Real Samples Analysis}

The water samples were collected at GM Peladang, 297 Lorong Fertigasi Padang Negara, 20400 Kuala Ibai, Kuala Terengganu, Terengganu Darul Iman, and the other two locations were at Jalan Biawak and a pond besides the School of Maritime Business and Management's building, Universiti Malaysia Terengganu. $\mathrm{pH}$ meter was used to measure $\mathrm{pH}$ of the water samples. The water samples were collected in plastic bottles and stored at $4{ }^{\circ} \mathrm{C}$ for preservation prior to analysis. $50 \mathrm{~mL}$ of water samples were measured using $100 \mathrm{~mL}$ of measuring cylinder and filtered using $0.45 \mu \mathrm{m}$ of nylon syringe filter to remove the suspended solid. The water samples were diluted using supporting electrolyte before conducting CV experiment.

\section{Results and Discussion Influence of Cleaning Process}

A cleaning process of SPGE is essential for electrochemical testing as it involves the cleaning steps to remove any possible impurities which may interfere with the analyte detection. Anodic peak current for bare cleaned SPGE was slightly higher compared to the bare uncleaned SPGE (Figure 3). This might be due to the removal of the impurities found on the surface of the electrode, which enhanced the interaction of the analyte on the electrode surfaces (Ahmad et al., 2016). 


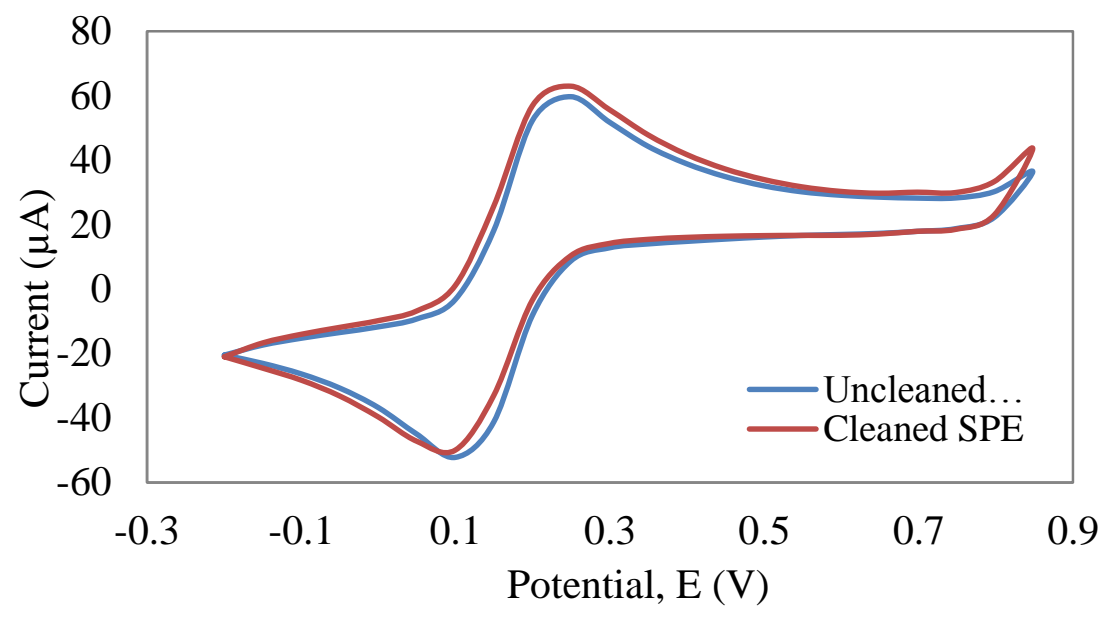

Figure 3: Cyclic voltammogram of bare gold electrode before and after cleaning process.

\section{Optimization of Parameters for Electrochemical Measurement \\ Influence of Scan Rates}

Five different scan rates were optimized in the presence of $5 \mathrm{mM} \mathrm{K} \mathrm{K}_{4} \mathrm{Fe}(\mathrm{CN})_{6}$ in $0.1 \mathrm{M} \mathrm{KCl}$, at the potential ranging between $-0.2 \mathrm{~V}$ to $0.8 \mathrm{~V}$. The result showed that when the scan rates increased, the peak-to-peak separation and peak current also increased. At very low scan rates, natural convection is known to affect the shape of experimental cyclic voltammograms (Zhang et al., 2010). However, longer time was consumed when decreasing the scan rate. Thus, scan rate value of 50 $\mathrm{mV} / \mathrm{s}$ was used for the optimization because lower scan rate gave an efficient kinetic of electron transfer. Figure 4 shows the voltammogram with different scan rates.

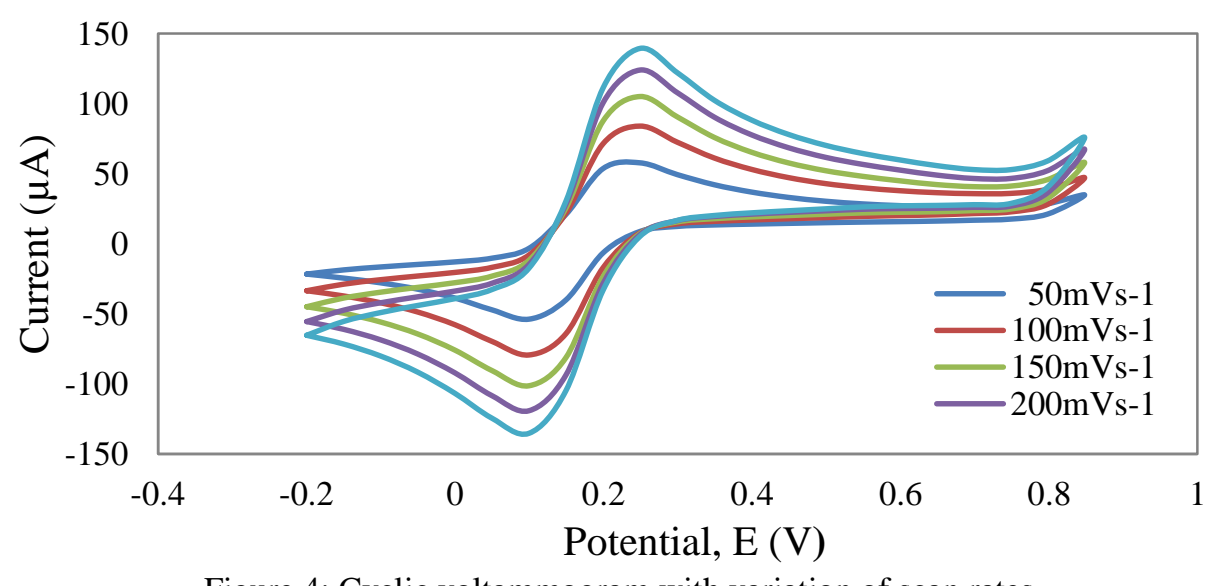

Figure 4: Cyclic voltammogram with variation of scan rates.

In addition, a theoretical expression for the peak current was derived as a function of scan rate, following Randles-Sevcik equation. The relationship between the anodic and cathodic peak current and the square root scan rate was plotted (Figure 5). The equation obtained can be expressed as $I_{p}(\mu \mathrm{A})=9.3917 \mathrm{~V}^{1 / 2}-9.2328$ for anodic peak current and $I_{p}(\mu A)=-9.3528 V^{1 / 2}+13.023$ for cathodic peak current. Both equations indicated the best linearity coefficient which was 0.9996 . At the slow scan rate, the diffusion layer was larger, leading to the lower concentration gradient to the electrode surface. Table 1 shows diffusion coefficient of anodic and cathodic peak current for variation scan rate. 
Figure 5: Square root of scan rates $(\mathrm{V} / \mathrm{s})$ against peak current $(\mu \mathrm{A})$.

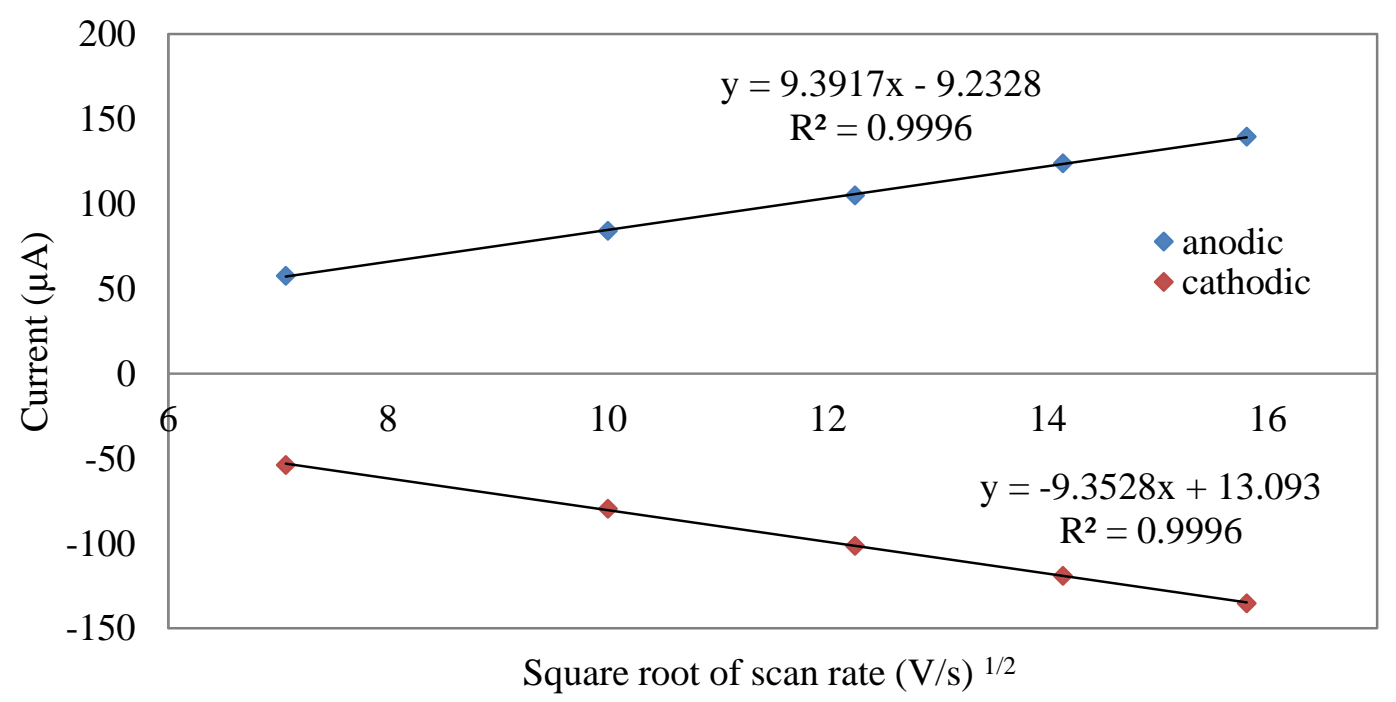

Table 1: Diffusion coefficient of anodic and cathodic peak current for variation scan rate.

\begin{tabular}{ccccc}
\hline $\begin{array}{c}\text { Scan rate } \\
(\mathbf{m V} / \mathbf{s})\end{array}$ & $\begin{array}{c}\text { Anodic peak } \\
\text { current }(\boldsymbol{\mu} \mathbf{A})\end{array}$ & $\begin{array}{c}\text { Cathodic peak } \\
\text { current }(\boldsymbol{\mu A})\end{array}$ & $\begin{array}{c}\text { Diffusion } \\
\text { coefficient, Ox } \\
\left(\mathbf{c m}^{\mathbf{2}} \mathbf{s}^{-1}\right)\end{array}$ & $\begin{array}{c}\text { Diffusion } \\
\text { coefficient, Red } \\
\left(\mathbf{c m}^{\mathbf{2}} \mathbf{s}^{-\mathbf{1}} \mathbf{)}\right.\end{array}$ \\
\hline 50 & 57.800 & -53.772 & $2.81 \times 10^{-7}$ & $2.43 \times 10^{-7}$ \\
100 & 84.106 & -79.437 & $2.97 \times 10^{-7}$ & $2.65 \times 10^{-7}$ \\
150 & 105.011 & -101.318 & $3.09 \times 10^{-7}$ & $2.87 \times 10^{-7}$ \\
200 & 123.992 & -119.110 & $3.23 \times 10^{-7}$ & $2.98 \times 10^{-7}$ \\
250 & 139.587 & -135.254 & $3.27 \times 10^{-7}$ & $3.07 \times 10^{-7}$ \\
\hline
\end{tabular}

\section{Influence of type of supporting electrolyte}

Several electrolytes were tested to obtain the best results with reference to IMI detection. Among the electrolytes, $5 \mathrm{mM} \mathrm{K}_{3} \mathrm{Fe}(\mathrm{CN})_{6}$ in $0.1 \mathrm{M} \mathrm{KCl}$ and $5 \mathrm{mM} \mathrm{K}_{4} \mathrm{Fe}(\mathrm{CN})_{6}$ in $\mathrm{B}-\mathrm{R}$ buffer showed the best results regarding the peaks separation and peak shapes. Figure 6 shows the voltammogram of SPGE using $5 \mathrm{mM} \mathrm{K}_{3} \mathrm{Fe}(\mathrm{CN})_{6}$ in both $\mathrm{KCl}$ and $\mathrm{B}-\mathrm{R}$ buffer. Both electrolytes showed welldefined shapes of voltammogram with different peak-topeak separation, in which $\mathrm{KCl}$ showed a lower peak-to- peak separation $(111.6 \mathrm{mV})$ compared with B-R buffer $(141.1 \mathrm{mV})$. Based on peak-to-peak separation values observed, there was significant difference of $29.5 \mathrm{mV}$ for both supporting electrolytes. Thus, $\mathrm{KCl}$ was used as the optimized supporting electrolyte for further measurement since a lower peak-to-peak separation indicating rapid kinetic transfer of electron occurred (Pan et al., 2014). The peak-to-peak separation of the anodic and cathodic peak potential was calculated using the following equation $\left(\Delta \mathrm{E}_{\mathrm{p}}=\mathrm{E}_{\mathrm{pa}}-\mathrm{E}_{\mathrm{pc}}\right)$. 


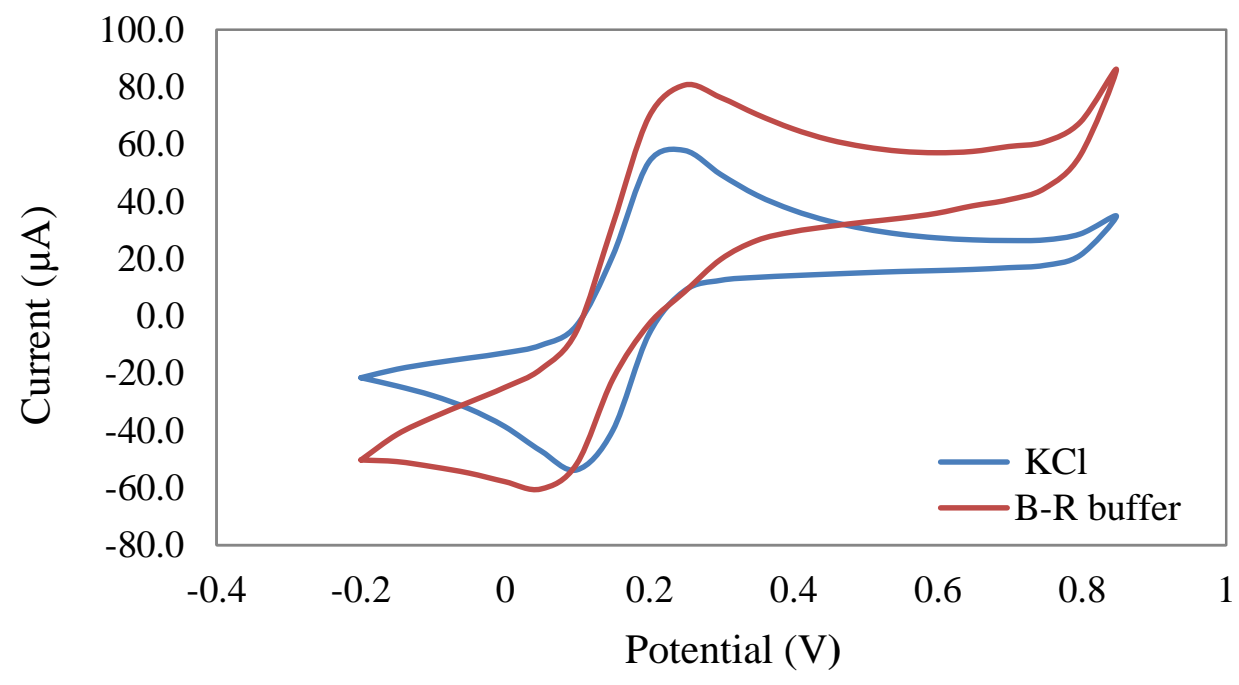

Figure 6: Voltammogram of the SPGE using $5 \mathrm{mM} \mathrm{K} \mathrm{K}_{3} \mathrm{Fe}(\mathrm{CN})_{6}$ in $\mathrm{KCl}$ and $\mathrm{B}-\mathrm{R}$ buffer.

\section{Influence of the pH of supporting electrolyte}

The $\mathrm{pH}$ has tremendous influence on the reduction of IMI. The peak current and potential of IMI reduction changed with the increment of $\mathrm{pH}$ from $\mathrm{pH} 2$ to 7. However, a previous study used wider increment of $\mathrm{pH}$ from $\mathrm{pH} 3$ to 11 . The best sensitivity and shape of the voltammograms were observed at $\mathrm{pH} 7.0$ for IMI reduction in sodium sulphate as supporting electrolyte (Samet et al., 2016). In this study, pH of supporting electrolytes was adjusted between $\mathrm{pH} 5$ - $\mathrm{pH} 9$ using 5\% of $\mathrm{HCl}$ and $\mathrm{KOH}$ solution. Within this $\mathrm{pH}$ range, IMI signal on SPGE slightly increased with the $\mathrm{pH}$ increase.
However, the reduction peak current slightly decreased at $\mathrm{pH}$ 8. The cathodic peak current for IMI detection was the highest at $\mathrm{pH}$ 7. The lowest peak current was observed at $\mathrm{pH} 5$, indicating that the IMI peak current started to increase when the $\mathrm{pH}$ of supporting electrolyte increased. At $\mathrm{pH}$ more than 7, the IMI reduction was not favorable in basic conditions. This result is similar to those reported by Majidi and co-workers (2011), where they found that the cathodic peak current for IMI was the highest at $\mathrm{pH} 7$ using 0.1 phosphate buffer solution (PBS) as supporting electrolyte (Majidi et al., 2011). Figure 7 shows the cathodic peak current at different $\mathrm{pH}$ of $5 \mathrm{mM} \mathrm{K}_{3} \mathrm{Fe}(\mathrm{CN})_{6}$ in $0.1 \mathrm{M} \mathrm{KCl}$.

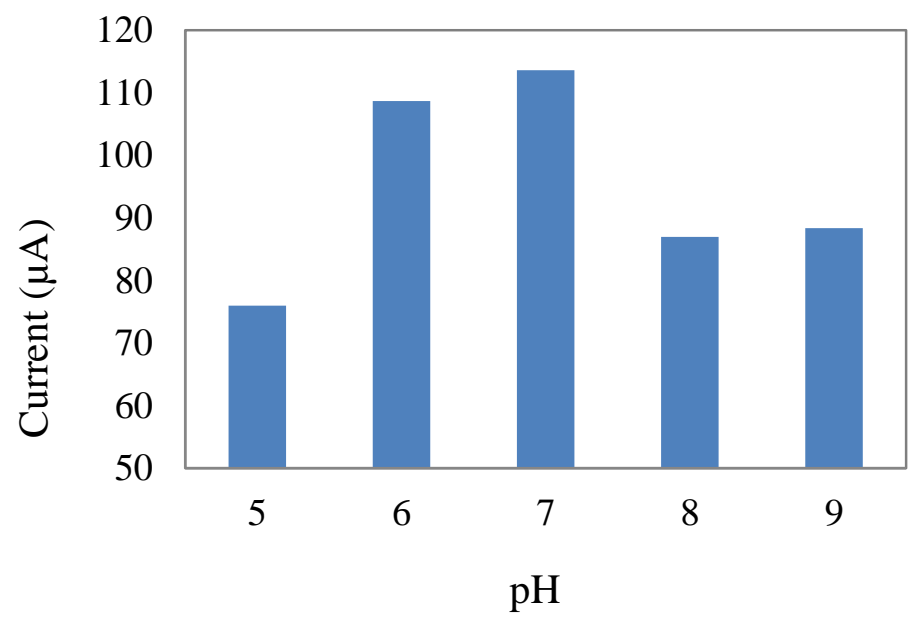

Figure 7: Peak current $(\mu \mathrm{A})$ at different $\mathrm{pH}$ of supporting electrolyte.

\section{Calibration Curve for IMI Standard}

The calibration curve for IMI concentration values of 1 to $10 \mathrm{mg} / \mathrm{L}$ was established using modified SPGE. A good linearity with the correlation coefficient of 0.9441 was obtained, showing that the concentration value was suitable for IMI detection in electrochemical method. Figure 8 shows the calibration curve for IMI standard in KCl. 


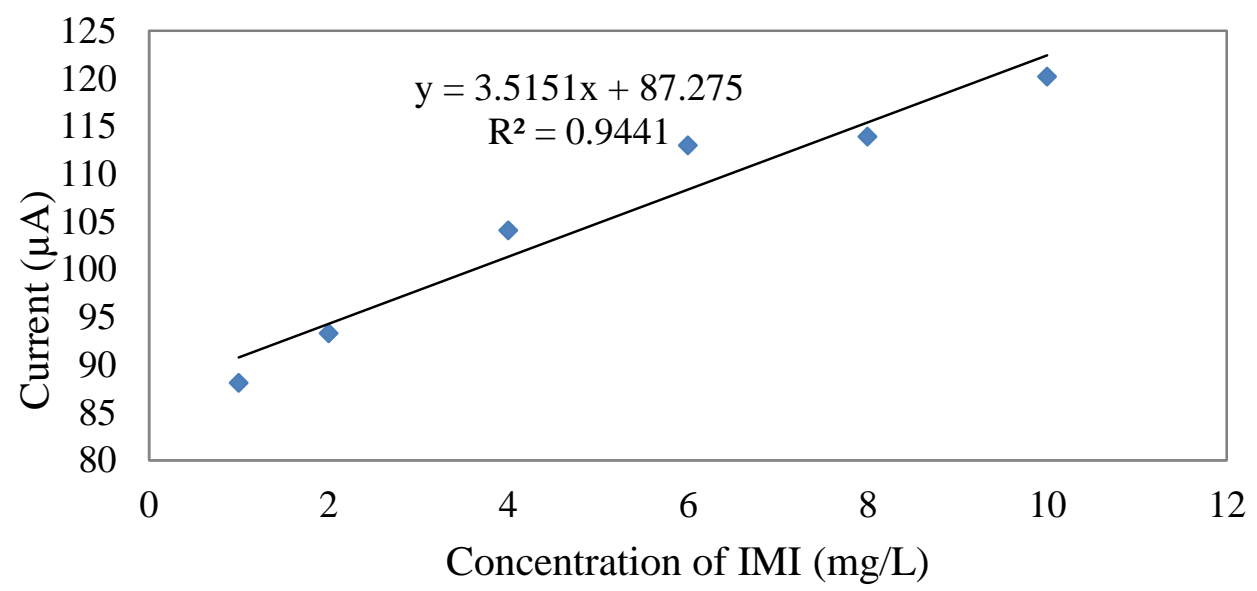

Figure 8: Calibration curve for IMI standard in $\mathrm{KCl}$.

\section{Characterization of modified electrode using Scanning Electron Microscopy}

The SPGE before and after modification were characterized using SEM to see the difference in surface morphology of both electrodes. From the observation, the granules of gold particles were spotted evenly on the surface of bare SPGE, whereas the modified SPGE showed that there was immobilization of SAM. Thus, it was confirmed that there was a presence of 11-MUA on the surface of the electrode. The magnification level of $\mathrm{X} 3500$ and $5 \mu \mathrm{m}$ of resolution, with $25 \mathrm{kV}$ of accelerating voltage were applied. Figure 9 shows the image of both electrodes.
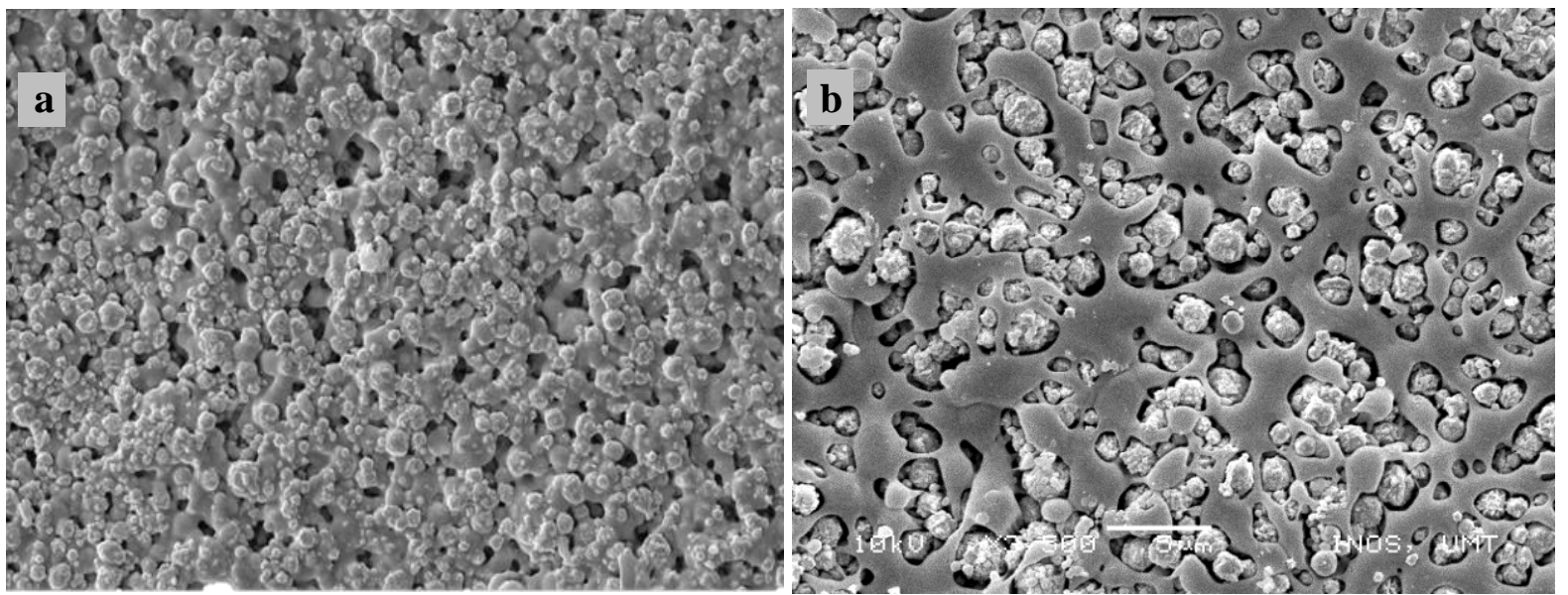

Figure 9: a) Surface of bare electrode and b) surface of modified electrode.

\section{Characterization of electrode using cyclic voltammetry}

Self-assembled monolayer (SAM) was performed on the surface of SPGE with 11-mercaptoundecanoic acid (11MUA). $10 \mathrm{mg} / \mathrm{L}$ of IMI was prepared in the optimized parameter of $5 \mathrm{mM} \mathrm{K}{ }_{3} \mathrm{Fe}(\mathrm{CN})_{6}$ in $0.1 \mathrm{M} \mathrm{KCl}$ at $\mathrm{pH}$, with scan rate of $50 \mathrm{mV} / \mathrm{s}$ and measured using $\mathrm{CV}$. The reduction peak of IMI for bare SPGE was observed at potential value of $-0.05 \mathrm{~V}$, whereas two oxidation peaks were observed at potential values of $0.15 \mathrm{~V}$ and $0.3 \mathrm{~V}$ (Figure 10). Meanwhile, the voltammagram of modified SPGE with 11-MUA showed that the current was suppressed and no redox reaction was observed due to the blocking of electron transfer to the electrode by 11MUA SAM. Thus, a well-packed formation of SAM on the electrode caused the peak-shape morphology on modified SPGE disappeared (Ahmad et al., 2012). 


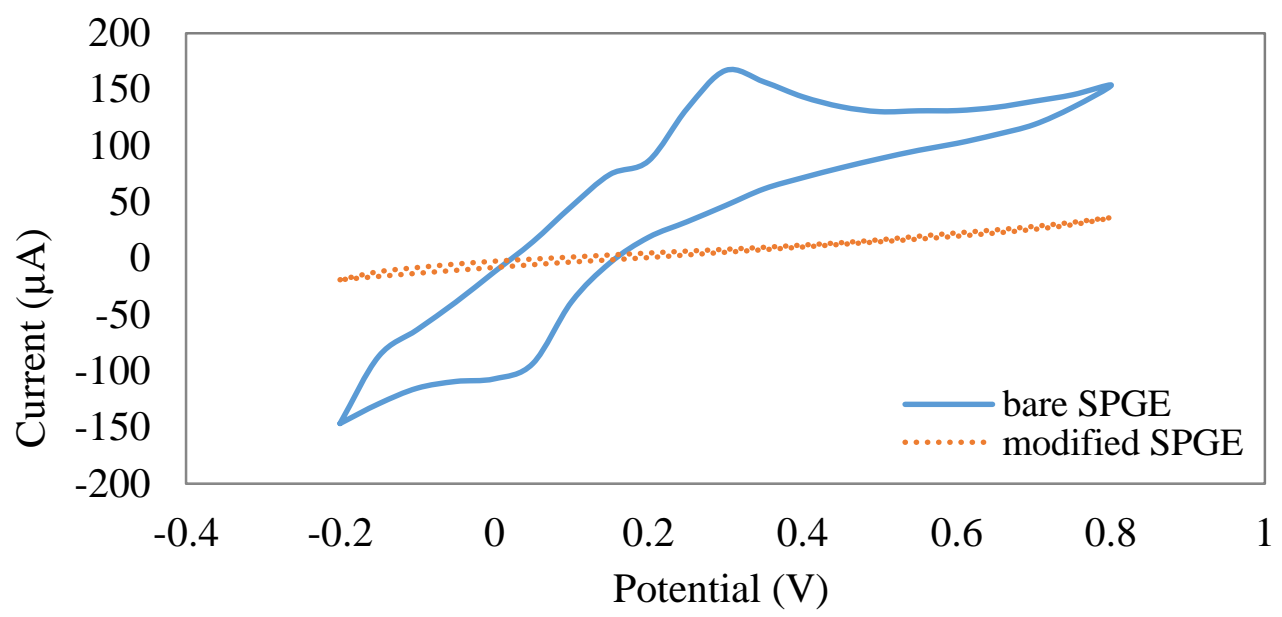

Figure 10: Potential (V) vs Current $(\mu \mathrm{A})$ of bare and modified SPGE in $10 \mathrm{mg} / \mathrm{L} \mathrm{IMI.}$

\section{Electrochemical measurement in water samples}

A calibration curve for IMI concentration values of 1 to $10 \mathrm{mg} / \mathrm{L}$ was established using modified SPGE. The presence of 11-MUA on the electrode's surface showed a negative slope of calibration curve obtained due to indirect measurements in $\mathrm{CV}$, in which formation of SAM blocked the transferring of electron to the electrode surface. Figure 11 shows that the concentration increased when the cathodic peak current decreased. At high concentration of IMI $(8-10 \mathrm{mg} / \mathrm{L})$, the electron was blocked from flowing to the electrode surface, resulting in a high suppressed current. Meanwhile, at low concentration of IMI (1-2 mg/L), the electrons were able to flow due to higher peak current detected compared to at higher concentration. A good correlation for six different concentration values of IMI was obtained with $\mathrm{R}^{2}=0.9051$.

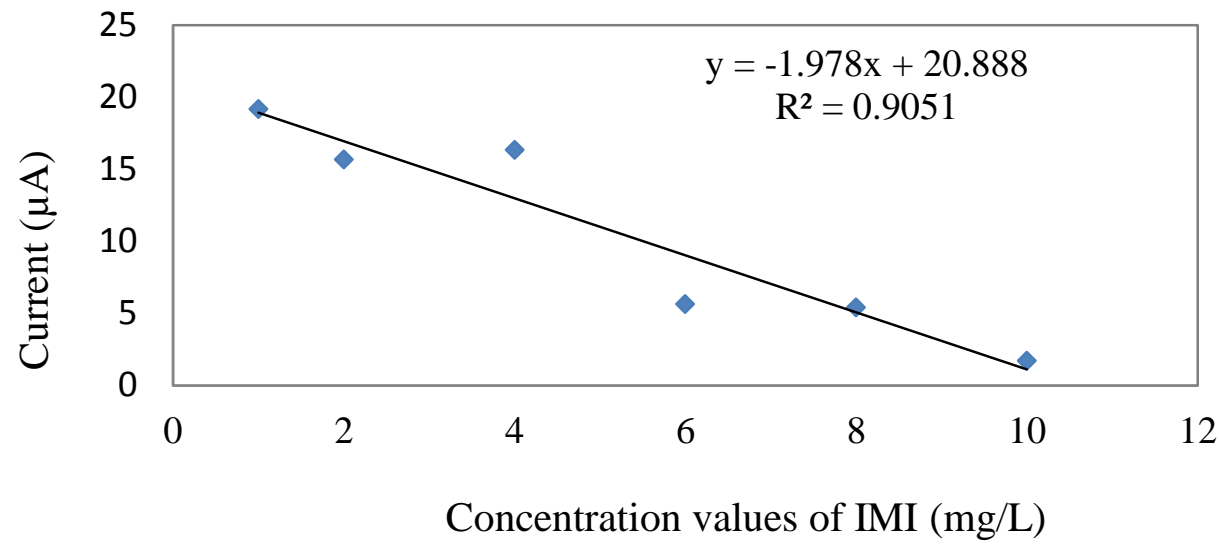

Figure 11: A calibration curve for IMI standard at modified SPGE.

The modified SPGE was used to detect the presence of IMI in water samples. The water samples collected at GM Peladang was detected using voltammogram with the lowest reduction peak current. The actual concentration of IMI detection was calculated for all water samples using the equation in calibration curve obtained at modified SPGE.

Table 2: IMI detection in real sample using modified SPGE electrode.

\begin{tabular}{lcc}
\hline \multicolumn{1}{c}{ Water samples } & Current $(\boldsymbol{\mu A})$ & Actual concentration values $(\mathbf{m g} / \mathbf{L})$ \\
\hline GM Peladang, KT & -7.72 & 6.657 \\
Jalan Biawak, UMT & -9.085 & 5.967 \\
Pond beside PPPPM, UMT & -11.790 & 4.600 \\
\hline
\end{tabular}

The concentration values of IMI in water samples collected at three sampling sites - two locations in UMT and one at GM Peladang, Kuala Terengganu-were listed in Table 2. GM Peladang showed the highest concentration value of IMI $(6.657 \mathrm{mg} / \mathrm{L})$ compared with other locations. A high concentration value of IMI from GM Peladang was expected due to various agricultural activities such as insecticide agents used to improve crop yield. 


\section{Conclusion}

This preliminary study investigated the use of modified SPGE for IMI determination in water samples. The essential parameters for electrochemical measurement were successfully optimized. In a real sample analysis, the water samples which were collected at GM Peladang showed high concentration value of IMI, whereas no IMI was detected in water samples collected at Jalan Biawak and pond besides PPPPM, UMT. The reduction peak current of modified electrode was lower than oxidation peak current; therefore, the use of working electrode such as carbon or platinum instead of gold electrode probably

\section{References}

Ahmad, A., Lee, P. K. \& Jusoh, N. S. (2016). A comparative study of thiols self-assembled monolayers on gold electrode. Middle-East Journal of Scientific Research, 24(6), 2152-2158.

Ahmad, A. \& Moore, E. (2012). Electrochemical immunosensor modified with self-assembled monolayer of 11-mercaptoundecanoic acid on gold electrodes for detection of benzo[a]pyrene in water. The Analyst, 137(24), 5839-5844.

Brahim, M. B., Ammar, H. B., Abdelhedi, R. \& Samet, Y. (2016). Electrochemical behavior and analytical detection of imidacloprid insecticide on a BDD electrode using square-wave voltammetric method. Chinese Chemical Letters, 27(5), 666-672.

Durovic, A., Stojanovic, Z., Snezana, K., Grahovac, N., Bursic, V., Vukovic, G. \& Suturovic, Z. (2016). Development and validation of chronopotentiometric method for imidacloprid determination in pesticide formulations and river water samples. International Journal of Analytical Chemistry, 1-11.

Goulson, D. (2013). An overview of the environmental risks posed by neonicotinoid insecticides. Journals of Applied Ecology, 50(4), 977-987.

Guzsvany, V., Papp, Z., Svancara, I. \& Vytras, K. (2011). Electroanalysis of insecticides at carbon paste electrodes with particular emphasis on selected neonicotinoid derivatives. Intech Open-Advances in Integrated Pest Management, 541-578.

Halimatunsadiah, A. B., Norida, M., Omar, D., \& Kamarulzaman, N. H. (2016). Application of pesticide in pest management: The case of lowland vegetable growers. International Food Research Journal, 23(1), 85-94. would improve current detection. Besides, the presence of other components also might contribute to the current detection. Thus, the extraction process helped to obtain valid data. Furthermore, other reagents used for electrode modification might improve the sensitivity of IMI detection.

\section{Acknowledgements}

The authors would like to acknowledge Universiti Malaysia Terengganu for funding this research and providing the facilities.

Hashim, Z., Bin, H. Y., Elias, S. M., Mazlan, N., How, V., Putra, U., \& De, S. (2016). Review Dietary Risk Assessment Of Imidacloprid Residue In Rice: The Use Of Quick, Easy, Cheap, Effective , Rugged And Safe ( Quechers ) Method: A Review . Department of Environmental and Occupational Health, Faculty of Medicine And Health Sciences, 2(2), 13-23.

Kumar, A., Verma, A., \& Kumar, A. (2013). Accidental human poisoning with a neonicotinoid insecticide, imidacloprid : A rare case report from rural India with a brief review of literature. Egyptian Journal of Forensic Sciences, 3(4), 123-126.

Liu, Z., Liu, J., Wang, K., Li, W, Shelver., Weilin, L., Li, Qing X., Li, Ji., Xu, Ting. (2015). Selection of phagedisplayed peptides for the detection of imidacloprid in water and soil. Analytical Biochemistry, 485, 2833.

Majidi, M. R., \& Ghaderi, S. (2017). Facile fabrication and characterization of silver nanodendrimers supported by graphene nanosheets: A sensor for sensitive electrochemical determination of Imidacloprid. Journal of Electroanalytical Chemistry, 792, 46-53.

Pan, X., Zhu K., Ren G., Islam, N., Warzywodac, J., and Fan. Z., (2014). Electrocatalytic properties of a vertically oriented graphene film and its application as a catalytic counter electrode for dye-sensitized solar cells. Journal of Materials Chemistry, A2, 12746-12753.

Sabourmoghaddam, N., Pauzi, M., \& Omar, D. (2015). Evidence for the microbial degradation of imidacloprid in soils of Cameron Highlands. Journal of the Saudi Society of Agricultural Sciences, 14(2), $182-188$.

Struger, J., Grabuski, J., Cagampan, S., Sverko, E., Mcgoldrick, D., \& Marvin, C. H. (2017). Chemosphere factors in fluencing the occurrence and distribution of neonicotinoid insecticides in surface 
waters of southern Ontario, Canada. Chemosphere, $169,516-523$.

Tonle, I. \& Ngameni, E. (2010). Pesticides in the Modern World - Trends in Pesticides Analysis. Page 465-488.
Zhang, J., Harris, A.R., Cattrall, R.W. \& Bond, A.M. (2010). Voltammetric ion-selective electrodes for the selective determination of cations and anions. Analytical Chemistry, 82 (5), 1624-1633. 